\title{
Non-genetic and genetic effects related to birth and weaning weights of crossbred dairy goats
}

\author{
J.F. Vázquez-Armijo ${ }^{1}$, A. Salvador-Cáceres ${ }^{2}$, N. Lopez-Villalobos ${ }^{1,3}$, J.B. Herrera-Ojeda", \\ A. García-Medina ${ }^{1}$ and G.M. Parra-Bracamonte ${ }^{5,6}$ \\ ${ }^{1}$ Autonomous University of Mexico State, Centro Universitario Temascaltepec, México \\ ${ }^{2}$ The Central University of Venezuela, Veterinary Sciences Faculty, Caracas, Venezuela \\ ${ }^{3}$ Massey University, School of Agriculture and Environment, Palmerston North, New Zealand \\ ${ }^{4}$ Technological Institute of the Valley of Morelia, Morelia, México \\ ${ }^{5}$ Instituto Politécnico Nacional, Center for Genomic Biotechnology, Reynosa, México
}

KEY WORDS: genetic parameters, heritability, heterosis, litter size, live weight traits

Received: 14 December 2020

Revised: $\quad 9$ March 2021

Accepted: $\quad 6$ June 2021

${ }^{6}$ Corresponding author:

e-mail: gparra@ipn.mx
ABSTRACT. The objectives of this study were to assess the effect of some non-genetic factors, breed and heterosis on birth weight and weaning weight in crossbred dairy kids, and to estimate genetic parameters of these traits in a multibreed dairy goat farm. Non-genetic analysis revealed that sex, year and season of birth and litter size are important factors that affect birth and weaning weights. Estimates of heritabilities for direct genetic effects were moderate at birth and weaning $(0.25 \pm 0.06$ and $0.24 \pm 0.10$, respectively). Heritability of maternal genetic effect for birth weight was $0.26 \pm 0.03$. The bivariate analysis also revealed that permanent maternal effects are significant for birth and weaning weights indicating that this component should be considered in management strategies. These results highlight the importance of considering non-genetic factors to design management strategies in combination with genetic selection strategies to improve the future performance of replacement of does.

\section{Introduction}

Dairy goat production is a socially, economically and culturally important part of the livestock industry in America (Lu and Miller, 2019). Milk, cheese and other dairy products are obtained from goat production systems as food products of high nutritional value ( $\mathrm{Lu}$ and Miller, 2019). The goat population in Latin America comprises approximately $3.5 \%$ of the world goat population, and of this proportion, $20 \%$ are dairy goats that are exploited in intensive production systems (AndradeMontemayor et al., 2019).

In Venezuela, goats were introduced during the Spanish colonization in the XV century and currently this country has the fourth-largest goat inven- tory in Latin America, with a population close to 2.2 million heads, managed at meat, meat and milk, and specialized milk production systems (Dickson et al., 2019). The main breeds used for these specialized production systems are Alpine, Nubian and Canary's breeds (Dickson et al., 2019).

One of the most important limitations identified in these systems is the absence of genetic improvement programmes and access to high genetic merit animals (Dickson et al., 2019). Genetic parameters (genetic variances, heritabilities and genetic correlations) are required to design breeding programmes with a systematic approach (Harris et al., 1984). These genetic parameters are specific to breeds and populations (Jembere et al., 2017). Birth and weaning weights are two of the most available traits in 
these goat production systems given that they are easy to measure and record. Mature live weight has been positively associated with milk yield and composition in dairy goats (Morris et al., 2011) and growth traits because birth weight is genetically associated with later live weight traits and adult size (Jembere et al., 2017).

So, the objectives of the study were to assess the effects of some non-genetic factors, breed and heterosis on birth weight (BW) and weaning weight (WW) in crossbred dairy kids and to estimate genetic parameters of these traits in a multi-breed dairy goat farm of Venezuela.

\section{Material and methods}

\section{Ethical aspects}

The data used in this study were collected during normal animal management practices and approval from an Animal Ethics Committee was not required.

\section{Source of data}

A database from a private intensive dairy farm 'Agroinversiones Los Isleños C.A.,' located in the town of Magdaleno, Zamora municipality, Aragua state, Venezuela, at $10^{\circ} 07^{\prime} \mathrm{N}$ and $67^{\circ} 35^{\prime} \mathrm{W}$, was made available for this study. The climate of the location is tropical savannah, with high humidity (around 80\%) due to its proximity to Lake Valencia, with an average temperature of $24.5^{\circ} \mathrm{C}$ and an average annual rainfall of $1200 \mathrm{~mm}$ as maximum (INE, 2011).

Records from 3782 kids collected from the year 2014 to the year 2018 were analysed. Each record included animal identification, BW and WW, dates of birth and weaning, sex of the kid, type of birth (single, twin and triplets), sire and dam identification and breed composition of the kid, sire and dam. The breeds present in the flock were Alpine, Canary, Saanen, Nubian and other breeds with minor representation. The proportion of each breed in the animal, sire and dam was not complete and estimation of specific heterosis between each pair of breeds was not possible, so a coefficient of general heterosis was derived for each animal following the approach given by Gregory and Cundiff (1980).

Kids management consisted primarily of omphalic prophylaxis and pasteurized colostrum administration, and a posterior daily artificial feeding with approximately 11 of milk until weaning on day 60. Generally, male kids were separated approximately two days after birth and slaughtered for sale. Only purebred or $15 / 16$ of crossbreeding proportion males were maintained in the flock. Most females were used as replacements depending on their genotype.

\section{Statistical analysis}

Analyses of variance for BW and WW adjusted to 60 day of age (WW60) were performed using a SAS Software (SAS Institute Inc., Cary, NC, USA). The general linear model was:

$$
\begin{gathered}
\mathrm{y}_{i j k l}=\mu+\mathrm{S}_{i}+\mathrm{A}_{j}+\mathrm{M}_{k}+\mathrm{L}_{l}+\beta_{1} \mathrm{p}^{\mathrm{A}}+\beta_{2} \mathrm{p}^{\mathrm{S}}+\beta_{3} \mathrm{p}^{\mathrm{C}}+ \\
\beta_{4} \mathrm{p}^{\mathrm{N}}+\beta_{5} \mathrm{~h}+\varepsilon_{i j k l}
\end{gathered}
$$

where: $\mathrm{y}_{i j k l}-\mathrm{BW}$ or WW60; $\mu$ - overall mean; $\mathrm{S}_{i}$ - fixed effect of sex $i^{\text {th }}$ of the kid; a - fixed effect of the $j^{\text {th }}$ year of birth; $\mathrm{M}_{k}$ - fixed effect of $k^{\text {th }}$ season of birth; $\mathrm{L}_{l}$ - fixed effect of $l^{\text {th }}$ litter size; $\mathrm{p}^{\mathrm{A}}, \mathrm{p}^{\mathrm{s}}, \mathrm{p}^{\mathrm{C}}$ and $\mathrm{p}^{\mathrm{N}}$ - proportion of Alpine, Saanen, Canary and Nubian breed in the kid; $h$ - coefficient of general heterosis; $\beta_{1}, \beta_{2}, \beta_{3}, \beta_{4}$ and $\beta_{5}$ - regression coefficients of BW or WW on a proportion of Alpine, Saanen, Canary and Nubian, and heterosis, respectively; and $\varepsilon_{i j k l}$ - residual error. The proportion of other breeds plus the proportion of unknown breed was not fitted in the model to constrain the regression coefficients for orthogonality and used as a base for comparison. Animals born as twins or triplets were considered in one class for the analysis. Four birth seasons were defined: from January to March, from April to June, from July to September, and from October to December. Leastsquares means for sex (only for BW), year, season and litter size were estimated and used for multiple mean comparisons using the Tukey test adjusted with a Bonferroni correction by the number of comparisons.

Estimates of variance components required for the estimation of genetic parameters were obtained using the MTDFREML software package (Van Vleck and Boldman, 1993) in which the convergence criterion used for all models was $-2 \log \mathrm{L}=1 \times 10^{-14}$. The pedigree consisted of 5145 total animals, with 137 sires and 1727 does.

The model for BW was expressed as:

$$
\mathrm{y}_{1}=\mathrm{X}_{1} \mathrm{~b}_{1}+\mathrm{Z}_{1} \mathrm{a}_{1}+\mathrm{W}_{1} \mathrm{~m}_{1}+\mathrm{C}_{1} \mathrm{p}_{1}+\mathrm{e}_{1}
$$

where: $y_{1}-$ vector of $B W$ values; $b_{1}-$ vector of fixed effects (contemporary group of animals born of the same litter size, year and season, sex and coefficient of general heterosis as a covariate); $a_{1}-$ vector of random direct animal genetic additive effects; $\mathrm{m}_{1}$ - vector of random maternal genetic additive effects; $p_{1}$ - vector of random permanent environmental maternal effects; $\mathrm{e}_{1}-$ vector of random residual effects; $\mathrm{X}_{1}, \mathrm{Z}_{1}, \mathrm{~W}_{1}$ and $\mathrm{C}_{1}$ - design matrices of the corresponding effects. The distributional properties of the elements in the model with $\mathrm{E}$ and $\mathrm{V}$ indicating the expectation and variance were as follows: 


$$
\begin{gathered}
\mathrm{E}\left[\begin{array}{c}
\mathrm{y}_{1} \\
\mathrm{a}_{1} \\
\mathrm{~m}_{1} \\
\mathrm{p}_{1} \\
\mathrm{e}_{1}
\end{array}\right]=\left[\begin{array}{c}
\mathrm{X}_{1} \mathrm{~b}_{1} \\
0 \\
0 \\
0 \\
0
\end{array}\right], \\
\mathrm{V}=\left[\begin{array}{c}
\mathrm{a}_{1} \\
\mathrm{~m}_{1} \\
\mathrm{p}_{1} \\
\mathrm{e}_{1}
\end{array}\right]\left[\begin{array}{ccccccc}
\mathbf{A} \sigma_{\mathrm{a}_{1}}^{2} & & \\
A \sigma_{\mathrm{a}_{1} \mathrm{~m}_{1}} & \mathbf{A} \sigma_{\mathrm{m}_{1}}^{2} & & & \\
0 & 0 & 0 & \mathbf{I}_{1} \sigma_{\mathrm{p}_{1}}^{2} & & \\
0 & 0 & 0 & 0 & 0 & 0 & \mathbf{I}_{2} \sigma_{\mathrm{e}_{1}}^{2}
\end{array}\right],
\end{gathered}
$$

where: a - numerator relationship matrix of order 5145 , the total number of animals in the pedigree file; $I_{1}$ - identity matrix of order 1727 , the number of does with offspring BW records; $\mathrm{I}_{2}$ - identity matrix of order 3782 , the number of $\mathrm{BW}$ records; $\sigma_{\mathrm{a}_{1}}^{2}$ variance of direct animal genetic additive effects for $\mathrm{BW} ; \sigma_{\mathrm{m}_{1}}^{2}-$ variance of maternal genetic effects for $\mathrm{BW} ; \sigma_{\mathrm{a}_{1} \mathrm{~m}_{1}}-$ covariance between direct animal genetic additive and maternal genetic effects for $\mathrm{BW}$; $\sigma_{\mathrm{p}_{1}}^{2}$ - variance of maternal permanent environment effects; and $\sigma_{\mathrm{e}_{1}}^{2}-$ variance of residual effects for BW. Estimates of heritability of direct additive genetic $\left(\mathrm{h}_{1}^{2}\right)$ and maternal genetic $\left(\mathrm{m}_{1}^{2}\right)$ effects and proportion of maternal permanent environment effects relative to phenotypic variance for $\mathrm{BW}$ were estimated as:

$$
\begin{gathered}
\mathrm{h}_{1}^{2}=\frac{\sigma_{\mathrm{a}_{1}}^{2}}{\sigma_{\mathrm{T}_{1}}^{2}}, \mathrm{~m}_{1}^{2}=\frac{\sigma_{\mathrm{m}_{1}}^{2}}{\sigma_{\mathrm{T}_{1}}^{2}} \text { and } \mathrm{p}_{1}^{2}=\frac{\sigma_{\mathrm{p}_{1}}^{2}}{\sigma_{\mathrm{T}_{1}}^{2}}, \\
\text { where } \sigma_{\mathrm{T}_{1}}^{2}=\sigma_{\mathrm{a}_{1}}^{2}+\sigma_{\mathrm{m}_{1}}^{2}+\sigma_{\mathrm{a}_{1} \mathrm{~m}_{1}}+\sigma_{\mathrm{p}_{1}}^{2}+\sigma_{\mathrm{e}_{1}}^{2} .
\end{gathered}
$$

Total heritability $\left(\mathrm{H}_{1}\right)$ for BW was estimated as:

$$
\mathrm{H}_{1}=\frac{\sigma_{\mathrm{a}_{1}}^{2}+1.5 \sigma_{\mathrm{a}_{1} \mathrm{~m}_{1}}+0.5 \sigma_{\mathrm{m}_{1}}^{2}}{\sigma_{\mathrm{T}_{1}}^{2}}
$$

The correlation between direct additive genetic and maternal genetic effects $\left(\mathrm{r}_{\mathrm{a}_{1} \mathrm{~m}_{1}}\right)$ was estimated as:

$$
\mathrm{r}_{\mathrm{a}_{1} \mathrm{~m}_{1}}=\frac{\sigma_{\mathrm{a}_{1} \mathrm{~m}_{1}}}{\sigma_{\mathrm{a}_{1}} \sigma_{\mathrm{m}_{1}}},
$$

with $\sigma_{\mathrm{a}_{1}}$ and $\sigma_{\mathrm{m}_{1}}$ the standard deviations of direct additive genetic and maternal genetic effects, respectively.

The model to obtain variance components for WW60 was the following:

$$
\mathrm{y}_{2}=\mathrm{X}_{2} \mathrm{~b}_{2}+\mathrm{Z}_{2} \mathrm{a}_{2}+\mathrm{C}_{2} \mathrm{p}_{2}+\mathrm{e}_{2},
$$

where: $b_{2}$ - vector of fixed effects including the effects of contemporary group and coefficient of general heterosis as a covariate; $a_{2}, p_{2}, Z_{2}$ and $\mathrm{C}_{2}$ - vectors and matrices as defined as above but for WW records. The distributional properties of the elements in the model for analysis of WW60 were as follows:

$$
\begin{gathered}
\mathrm{E}\left[\begin{array}{c}
\mathrm{y}_{2} \\
\mathrm{a}_{2} \\
\mathrm{p}_{2} \\
\mathrm{e}_{2}
\end{array}\right]=\left[\begin{array}{c}
\mathrm{X}_{2} \mathrm{~b}_{2} \\
0 \\
0 \\
0
\end{array}\right], \\
\mathrm{V}=\left[\begin{array}{c}
\mathrm{a}_{2} \\
\mathrm{~m}_{2} \\
\mathrm{p}_{2} \\
\mathrm{e}_{2}
\end{array}\right]\left[\begin{array}{ccc}
\mathbf{A} \sigma_{\mathrm{a}_{2}}^{2} & \\
0 & \mathbf{I}_{3} \sigma_{\mathrm{p}_{2}}^{2} & \\
0 & 0 & \mathbf{I}_{4} \sigma_{\mathrm{e}_{2}}^{2}
\end{array}\right],
\end{gathered}
$$

where: $\mathrm{I}_{3}$ - identity matrix of order 987, the number of does with offspring WW60 records; $\mathrm{I}_{4}$ - identity matrix of order 987, the number of WW60 records; $\sigma_{\mathrm{a}_{2}}^{2}-$ variance of direct animal genetic additive effects for WW60; $\sigma_{\mathrm{p}_{2}}^{2}$ - variance of maternal permanent environment effects; and $\sigma_{\mathrm{e}_{2}}^{2}-$ variance of residual effects for WW60. Estimates of heritability of direct additive genetic $\left(\mathrm{h}_{2}^{2}\right)$ and proportion of maternal permanent environment effects relative to phenotypic variance for WW60 were estimated as:

$$
\mathrm{h}_{2}^{2}=\frac{\sigma_{\mathrm{a}_{2}}^{2}}{\sigma_{\mathrm{T}_{2}}^{2}} \text { and } \mathrm{p}_{2}^{2}=\frac{\sigma_{\mathrm{p}_{2}}^{2}}{\sigma_{\mathrm{T}_{2}}^{2}} \text {, where } \sigma_{\mathrm{T}_{2}}^{2}=\sigma_{\mathrm{a}_{1}}^{2}+\sigma_{\mathrm{p}_{1}}^{2}+\sigma_{\mathrm{e}_{1}}^{2} \text {. }
$$

These univariate models described above were selected by a formerly exploratory comparison between models computed using a likelihood ratio test (Lynch and Walsh, 1998) as, $\lambda=-2(\log$ L Mmodel Log L Umodel), where Mmodel is the complete multivariate model and Umodel is the reduced multivariate model with covariance values of traits fixed to zero. Test statistic was considered as approximately distributed chi-square, with degrees of freedom equal to the difference in parameters between models, and an $\alpha=0.01$.

From univariate selected models a bivariate analysis of BW and WW was fitted, and the model was as follows:

$$
\begin{gathered}
{\left[\begin{array}{l}
\mathrm{y}_{1} \\
\mathrm{y}_{2}
\end{array}\right]=\left[\begin{array}{cc}
\mathrm{X}_{1} & 0 \\
0 & \mathrm{X}_{2}
\end{array}\right]\left[\begin{array}{l}
\mathrm{b}_{1} \\
\mathrm{~b}_{2}
\end{array}\right]+\left[\begin{array}{cc}
\mathrm{Z}_{1} & 0 \\
0 & \mathrm{Z}_{2}
\end{array}\right]\left[\begin{array}{l}
\mathrm{a}_{1} \\
\mathrm{a}_{2}
\end{array}\right]+\left[\begin{array}{cc}
\mathrm{W}_{1} & 0 \\
0 & 0
\end{array}\right]\left[\begin{array}{c}
\mathrm{m}_{1} \\
0
\end{array}\right]+} \\
{\left[\begin{array}{cc}
\mathrm{C}_{1} & 0 \\
0 & \mathrm{C}_{2}
\end{array}\right]\left[\begin{array}{l}
\mathrm{p}_{1} \\
\mathrm{p}_{2}
\end{array}\right]+\left[\begin{array}{l}
\mathrm{e}_{1} \\
\mathrm{e}_{2}
\end{array}\right] .}
\end{gathered}
$$

The distributional properties of the elements in the model with $\mathrm{E}$ and $\mathrm{V}$ indicating the expectation and variance were as follows:

$$
\mathrm{E}\left[\begin{array}{c}
\mathrm{y}_{1} \\
\mathrm{y}_{2} \\
\mathrm{a}_{1} \\
\mathrm{a}_{2} \\
\mathrm{~m}_{1} \\
\mathrm{p}_{1} \\
\mathrm{p}_{2} \\
\mathrm{e}_{1} \\
\mathrm{e}_{2}
\end{array}\right]=\left[\begin{array}{c}
\mathrm{X}_{1} \mathrm{~b}_{1} \\
\mathrm{X}_{2} \mathrm{~b}_{2} \\
0 \\
0 \\
0 \\
0 \\
0 \\
0 \\
0
\end{array}\right] .
$$


Estimates of variance and covariance components were used to compute heritabilities for direct and maternal (only for BW) effects, permanent and environmental effects of the studied traits. Estimates of heritability for direct $\left(\mathrm{h}^{2}\right)$ and maternal $\left(\mathrm{m}^{2}\right)$ genetic effects (for BW only), the genetic correlation between direct effects of BW and WW60, the genetic correlation between maternal (BW) and direct BW and WW60 effects, the proportion of permanent maternal effects relative to phenotypic variance $\left(p^{2}\right)$ for BW and WW60 and their correlation, and the proportion of environmental effects relative to phenotypic variance $\left(\mathrm{e}^{2}\right)$ for BW and WW60 and their correlation.

\section{Results}

The least-squares means for sex, year of birth, season and litter size for BW and WW60 are presented in Table 1. The effects of all fixed factors considered in the analysis of variance for BW were significant $(P \leq 0.5)$. Male kids were heavier at birth $(P<0.001)$ than female kids. Birth weight varied across years with kids born in the year 2014 showing the highest BW. For litter size, $75 \%$ of births were singlets and 25\% were multiples. Differences in BW were significant among single and multiple litter kids; kids born as singlets were $0.320 \mathrm{~kg}$ heavier than kids born as twins or triplets $(P<0.001)$.

Table 1. Least-squares means \pm standard error (SE) for birth weight (BW) and weaning weight at day 60 of age (WW60) in crossbred dairy goat neonates by sex, year, season and litter size

\begin{tabular}{crlll}
$\begin{array}{l}\text { Source of } \\
\text { variation }\end{array}$ & $n$ & BW, kg & $n$ & WW60, kg \\
\hline Sex & & $P<0.001$ & & \\
$\quad$ male & 1534 & $2.321^{\mathrm{a}} \pm 0.021$ & & \\
$\quad$ female & 1904 & $1.996^{\mathrm{b}} \pm 0.020$ & & \\
Year & & $P<0.001$ & & $P<0.001$ \\
2014 & 948 & $2.438^{\mathrm{a}} \pm 0.029$ & & \\
2015 & 763 & $2.187^{\mathrm{b}} \pm 0.030$ & 296 & $10.017^{\mathrm{a}} \pm 0.128$ \\
2016 & 656 & $2.116^{\mathrm{b}} \pm 0.031$ & 255 & $9.299^{\mathrm{b}} \pm 0.126$ \\
2017 & 631 & $1.912^{\mathrm{c}} \pm 0.032$ & 273 & $7.894^{\mathrm{d}} \pm 0.114$ \\
2018 & 440 & $2.137^{\mathrm{b}} \pm 0.040$ & 158 & $8.752^{\mathrm{c}} \pm 0.146$ \\
Season & & $P=0.012$ & & $P=0.601$ \\
Jan-Mar & 1019 & $2.117^{\mathrm{ab}} \pm 0.025$ & 338 & $9.016 \pm 0.191$ \\
Apr-Jun & 871 & $2.107^{\mathrm{b}} \pm 0.027$ & 195 & $8.998 \pm 0.208$ \\
Jul-Sep & 700 & $2.212^{\mathrm{a}} \pm 0.031$ & 198 & $8.940 \pm 0.203$ \\
Oct-Dec & 848 & $2.198^{\mathrm{ab}} \pm 0.029$ & 256 & $8.801 \pm 0.186$ \\
Litter size & & $P<0.001$ & & $P<0.001$ \\
1 & 2577 & $2.320^{\mathrm{a}} \pm 0.016$ & 779 & $9.221^{\mathrm{a}} \pm 0.167$ \\
2 and 3 & 861 & $1.997^{\mathrm{b}} \pm 0.026$ & 208 & $8.657^{\mathrm{b}} \pm 0.194$ \\
\hline
\end{tabular}

$\mathrm{n}$ - number of observations varied among sources of variation because of missing information; ${ }^{a-d}$ - means within each factor with different superscrips are statistically different at $P<0.05$
Only female kids were raised and therefore a significant reduction $(>70 \%)$ in the number of records with WW60 was observed. Mean WW60 was significantly reduced from 2015 to 2017 . Female kids born as singlets were $0.566 \mathrm{~kg}$ heavier $(P<0.001)$ at weaning than females kids born as twins or triplets. Effect of season of kidding was significant on BW $(P=0.012)$, but not on WW60. Kids born from July to September were heavier than kids born from April to June.

The breed and heterosis effects on BW and WW60 are presented in Table 2. Effects of Saanen and Nubian breeds were negative and significant $(P<0.001)$ on BW. Breed effects on WW60 were not significant. Heterosis effects on BW and WW60 were not significant.

Table 2. Breed and heterosis effects \pm standard error (SE) for birth weight (BW) and weaning weight at day 60 of age (WW60) of dairy goat neonates

\begin{tabular}{llllll}
\hline \multirow{2}{*}{ Breed effects } & BW & & \multicolumn{3}{l}{ WW60 } \\
\cline { 2 - 3 } \cline { 5 - 6 } & estimate & SE & & \\
\hline Mean & 2.244 & 0.750 & & 9.201 & 1.726 \\
Alpine & -0.113 & 0.079 & & 0.241 & 0.504 \\
Canary & -0.147 & 0.083 & & -0.623 & 0.539 \\
Saanen & $-0.288^{* *}$ & 0.084 & & 0.425 & 0.510 \\
Nubian & $-0.312^{* *}$ & 0.104 & & 0.092 & 0.537 \\
Heterosis & -0.023 & 0.041 & & 0.102 & 0.225 \\
\hline
\end{tabular}

** $-P<0.001$

Estimates of variance components and genetic parameters for BW and WW obtained from univariate models are presented in Table 3 . In the univariate analysis for both BW and WW60, the estimates of heritabilities for the direct additive genetic were moderate. For BW, the estimate of heritability for maternal additive genetic effect was moderate.

Table 3. Variance components and genetic parameters for birth weight (BW) and weaning weight at day 60 of age (WW60) of crossbred kids from univariate analyses

\begin{tabular}{|c|c|c|c|c|c|}
\hline \multicolumn{3}{|c|}{ Variance components } & \multicolumn{3}{|c|}{ Genetic parameters } \\
\hline Indices & BW & WW60 & Indices & BW & WW60 \\
\hline$\overline{\sigma_{a}^{2}}$ & 0.118 & 0.589 & $h^{2}$ & $0.25 \pm 0.064$ & $0.24 \pm 0.100$ \\
\hline$\sigma_{m}^{a^{d}}$ & 0.168 & - & $m^{2}$ & $0.35 \pm 0.031$ & - \\
\hline$\sigma_{a m}^{m}$ & -0.078 & - & $r_{d m}$ & $-0.55 \pm 0.067$ & - \\
\hline$\sigma^{2}$ & 0.018 & 0.410 & $p^{2}$ & $0.038 \pm 0.001$ & $0.16 \pm 0.064$ \\
\hline$\sigma_{e}^{p}$ & 0.254 & 1.501 & $e^{2}$ & $0.55 \pm 0.047$ & $0.60 \pm 0.096$ \\
\hline$\sigma^{e}{ }_{T}^{e}$ & 0.481 & 2.501 & $H^{2}$ & 0.18 & 0.24 \\
\hline
\end{tabular}

$\sigma^{2}{ }_{a}$ - direct additive genetic variance; $\sigma_{m}^{2}$ - maternal additive genetic variance; $\sigma_{p}^{2}$ - maternal permanent environment variance; $\sigma^{2}{ }_{e}$ - environmental variance; $\sigma_{T}^{2}-$ total phenotypic variance; $h^{2}$ - direct heritability; $m^{2}$ - maternal heritability; $r_{d m}$ - genetic correlation between direct and maternal effects; $p^{2}-$ proportion of maternal permanent environment effects relative to phenotypic variance; $e^{2}$ - environmental effects relative to phenotypic variance; total heritability: $H^{2}=\left(\sigma_{a}^{2}+1.5 \sigma^{2}{ }_{a m}+0.5 \sigma_{m}^{2}\right) / \sigma_{T}^{2}($ Willham, 1972) 
The estimate of genetic correlation between direct and maternal genetic effects for BW was negative but close to zero. The proportion of the total variance explained by the variance of maternal permanent $\left(\mathrm{p}^{2}\right)$ effects for $\mathrm{BW}$ was small and slightly greater for WW60. Conversely, environmental residual effects explained most proportion of phenotypic variance for both traits (Table 3).

Estimates of genetic parameters for BW and WW60 obtained from the bivariate analysis are presented in Table 4. The bivariate analysis produced similar estimates of heritability for direct additive genetic effects for BW to the estimates from the univariate analysis. However, the estimate of heritability of direct additive genetic effects for WW60 from the bivariate analysis was slightly smaller compared to the estimate from the univariate analysis.

Table 4. Heritabilities and genetic and phenotypic correlations for birth weight (BW) and weaning weight at day 60 of age (WW60) of crossbred kids from bivariate analyses

\begin{tabular}{lrll}
\hline Trait & \multicolumn{1}{l}{ BWa } & \multicolumn{1}{l}{ BWm } & WW60a \\
\hline BWa & $\mathbf{0 . 2 4} \pm 0.001$ & & 0.47 \\
BWm & $-0.21 \pm 0.001$ & $\mathbf{0 . 1 4} \pm 0.001$ & \\
WW60a & $0.50 \pm 0.001$ & $-0.10 \pm 0.001$ & $\mathbf{0 . 1 8} \pm \mathbf{0 . 0 0 1}$ \\
\hline
\end{tabular}

$\mathrm{BWa}$ - direct genetic additive effect for BW; BWm - maternal genetic effect for BW; WW60a - direct genetic additive effect for WW60; Heritabilities are on the diagonal, genetic correlations are below the diagonal and phenotypic correlation is above the diagonal

The estimate of heritability of maternal genetic effects for BW was $0.140 \pm 0.001$ from the bivariate analysis, which was slightly smaller $(0.17)$ than the estimate obtained from the univariate analysis. The genetic correlation between direct genetic additive effects for BW and WW60 was positively moderate $(0.50 \pm 0.001)$. The estimate of genetic correlation between the direct genetic additive effects for BW and maternal genetic effects for BW was negative $(-0.21)$, which was greater than the estimate obtained from the univariate analysis $(-0.078)$. The estimate of genetic correlation between the maternal genetic effects for $\mathrm{BW}$ and direct genetic additive effects for WW60 was low negative $(-0.10)$. The estimates of the proportion of maternal permanent effects with respect to the total variance obtained from the bivariate analysis were 0.13 and 0.21 for $\mathrm{BW}$ and WW60, respectively (estimates not shown), which were slightly greater than the estimates from univariate analysis $(0.038$ and 0.16 for $\mathrm{BW}$ and WW60, respectively). The estimate of the correlation between maternal permanent effects for BW and WW60 was strong positive $(0.96 \pm 0.001)$.

\section{Discussion}

Effects of environmental and genetic factors on BW and WW60 of kids from does in an intensive dairy goat production from Venezuela were evaluated. Both traits were significantly affected by the birth year and litter size. Breed and season effects were significant only on BW.

The importance of these live weight traits are not evident for dairy goat farms; however, the birth conditions are related to survival and milk production when the kids become milk producers. Dwyer et al. (2016) indicated that the main risk factors for mortality in small ruminants are low birth weight, particularly owing to poor maternal nutrition during gestation, dystocia, litter size and genetics. Moreover, the genetic correlations among the live weight measures at different ages of the animals are strong positive (Jembere et al., 2017), and the genetic correlations between live weight and milk production in dairy goats have been reported moderate positive (0.47) (Morris et al., 2011; Scholtens et al., 2018). Additionally, quantification of the pre-weaning performance of small ruminants from different birth and rearing types has multiple uses including providing informative biological parameters for the development of bioeconomic models but also in farmbased real-time decision support tools (McHugh et al., 2017).

Differences in BW by sex have been reported in several studies indicating that male kids are heavier than female kids in different goat breeds (Boujenane and El Hazzab, 2008; Zhang et al., 2008; Menezes et al., 2016), which is also confirmed in the present study.

The effect of birth year is related mostly to management and other environmental conditions which are specific for each year. The importance of this source of variation has been associated with changes in weather conditions during the years, which might affect feed availability and quality and animal welfare (Menezes et al., 2016). Although no information was available to justify between-year variations, it is very likely that management could have an influence on these changes.

Type of birth (single or multiple) recurrently is reported as an important factor affecting BW and other live weight traits in different studies assessing goat performance (Boujenane and El Hazzab, 2008; Zhang et al., 2008; Menezes et al., 2016), which was also found in this study.

Breed effects were only significant on BW. A pure Saanen kid was $0.288 \mathrm{~kg}$ lighter at birth 
compared to the average of the population, and a pure Nubian kid would be $0.312 \mathrm{~kg}$ lighter than the average of the population. Crossbreeding, considering either terminal or rotational crossing, synthetic breed creation or breed replacement, is often used to increase farmers' income through the improvement of productivity of local livestock (Leroy et al., 2016). Most production systems use crossbreeding to influence animal performance by heterosis giving priority to milk yield. The heterosis effects for BW and WW60 were not significantly different from zero. Although not enough documented some available evidence on heterosis for BW in a multi-breed herd in Mexico are positive and significant (Meza-Herrera et al., 2019). Given the priority of this production system, consideration of early growth performance would be important in order to guarantee the survival of replacement animals for posterior milk production putting an emphasis on complete records that may allow a more complete evaluation of performance among the crossbred genetic groups and support management of the best genetic groups.

The estimate of $h^{2}$ for direct additive genetic BW was moderate and similar to the estimates reported by Meza-Herrera et al. (2019) in the multi-breed goat population $(0.20-1.25)$. Estimates from other studies in other domestic animals have found that BW is from a moderately to a highly heritable trait (Koots et al., 1994; Gowane et al., 2010; Shokrollahi and Baneh, 2012). Jembere et al. (2017) reported from a large review a mean value of 0.16 for $\mathrm{h}^{2}$ of direct additive genetic effects for BW, and Visser (2019) reported a moderate heritability (0.15-0.16) for BW in different goat meat breeds of Africa. The estimate of $\mathrm{h}^{2}$ for direct additive genetic effects for WW60 was moderate and was equal to the mean value presented by Jambere et al. (2017) for live weight at two months of age in different goat breeds. The estimate of heritability of maternal genetic effects for BW from the univariate analysis was low but within the range reported in several studies (0.05-0.28) in different breeds (Zhang et al., 2008; Jembere et al., 2017, Menezes et al., 2018; Meza-Herrera et al., 2019). The estimates of $h^{2}$ for maternal genetic effects for $\mathrm{BW}$ found in the literature $\left(\mathrm{m}^{2}=0.27\right.$, Jamebere et al. (2017)) is smaller than the estimate obtained from the univariate analysis but greater than the estimate obtained from the bivariate analysis of this study, perhaps influenced by the reduction of the observations compared by the univariate analysis.
In general, the estimates of genetic correlations between direct additive genetic and maternal genetic effects have been reported negative for BW and other preweaning growth traits ranging from -0.07 to -0.89 (Boujenane and El Hazzab et al., 2008; Zhang et al., 2008; Meza-Herrera et al., 2019). This effect has been attributed to the data structure and availability and repeated maternal allowing the accurate partition of the phenotypic variance into all maternal (co)variance components (Maniatis and Pollott, 2003), in the present study although enough information of sire was available (average 25 kids per sire), information of dam was reduced (average 1.9 kid per doe).

The estimates of $\mathrm{p}^{2}$ for BW and WW60 were low (0.04 and 0.16, respectively). Zhang et al. (2008) reported higher $\mathrm{p}^{2}$ estimates for BW in Boer kids, and Barazandeh et al. (2012) reported higher estimates for BW but similar for WW60 in Raini Cashmere kids. Similarly, Jembere et al. (2017) reported a slightly larger estimate of $\mathrm{p}^{2}$ for BW (0.09) but lower for WW60 (0.04). Even when the reports define this effect as permanent for BW, it must be considered as a special case of a maternal effect due to common maternal effects on the progeny (Kruuk and Hadfield, 2007). This important effect is mostly conditioned by different factors related to the mothering ability and capacity during the gestational period (Matika et al., 2003; Räsänen and Kruuk, 2007; Mrode, 2014). It has been suggested that maternal environmental influence is overall produced by gestational conditions, which are closely tied to passive immunity, cytoplasmic inheritance, nutrition and maternal constraints on foetal growth and maternal intrauterine environment, as well as pre-weaning nutrition (Bradford, 1972; Cundiff, 1972; Matika et al., 2003). In this study, the model for WW60 did not consider the genetic maternal effects because the kids were separated from the mothers and raised in an artificial feeding system. However, the estimate of $\mathrm{p}^{2}$ for WW60 was moderate (0.16) indicating that the maternal permanent environment provided during gestation may remain until weaning even when the mothers lost contact with the progeny.

Determining the actual genetic sources of variation of different productive traits relies on the possibility of unravelling confounding environmental effects from direct additive genetic effects based on good data and effective statistical models (Kruuk and Hadfield, 2007). A data structure can be limiting when fitting complex models and determining unbiased estimators (Bijma, 2006). In the present 
study, also the reduced WW60 observations perhaps influenced the possible isolation of genetic effects.

The genetic parameters estimated in this study indicate that selection responses for BW and WW60 can be obtained if the selection is based on direct genetic additive and maternal genetic effects for BW and direct genetic additive for WW60. Further analysis including other productive traits might corroborate a positive correlation among preweaning growth size and milk yield potential in this multibred population.

\section{Conclusions}

Under the conditions of the dairy goat farm considered in this study the sex of the kid, year and season of birth, litter size and breed were important factors affecting early live weight traits. Therefore it would be important to consider these parameters in management decisions. Estimates of heritability for direct genetic additive effects for birth and weaning weights are moderate suggesting positive genetic responses to selection for these traits. Permanent maternal environmental effects were present for birth and weaning weights suggesting that this component should be considered in management strategies. This study also highlights the importance of using a more precise recording system for birth- and weaning-related data to generate accurate genetic evaluations.

\section{Acknowledgements}

The authors want to thank The Agroinversiones Los Isleños, C.A. for the collaboration and contribution of the analyzed data.

\section{Conflict of interest}

The authors declare that there is no conflict of interest.

\section{References}

Andrade-Montemayor H.M., Bidot Fernández A.I., Arias Azurdia R., Candido Ribeiro A., Dickson L., Celi Mariátegui I.D.R., Dayenoff Rucik P.M., Russi Mor A.C., 2019. Goat milk production in Latin America: generalities (the numbers) (in Spanish: Producción de leche de cabra en Latinoamerica: Generalidades (Los números)). In: C. Santos Sotomaior, P.M. Dayenoff Rucik, V.H. Parraguez Gamboa, ALEPRyCS (Editors). Sheep, Goats and Camelids in Latin America: Production, Health and Marketing (in Spanish: Ovejas, cabras y camélidos en Latinoamérica: producción, salud y comercialización). PUCPRESS. Curitiba (Brasil), pp. 188-204, https://doi.org/10.7213/B45-565
Barazandeh A., Moghbeli S.M., Vatankhah M., Mohammadabadi M., 2012. Estimating non-genetic and genetic parameters of preweaning growth traits in Raini Cashmere goat. Trop. Anim. Health Prod. 44, 811-817, https://doi.org/10.1007/s11250011-9971-5

Bijma P., 2006. Estimating maternal genetic effects in livestock. J. Anim. Sci. 84, 800-806, https://doi.org/10.2527/2006.844800x

Boujenane I., El Hazzab A., 2008. Genetic parameters for direct and maternal effects on body weights of Draa goats. Small Rumin. Res. 80, 16-21, https://doi.org/10.1016/j. smallrumres.2008.07.026

Bradford G.E., 1972. The role of maternal effects in animal breeding: VII. Maternal effects in sheep. J. Anim. Sci. 35, 1324-1334, https://doi.org/10.2527/jas1972.3561324x

Cundiff L.V., 1972. The role of maternal effects in animal breeding: VIII. Comparative aspects of maternal effects. J. Anim. Sci. 35, 1335-1337, https://doi.org/10.2527/jas1972.3561335x

Dickson L., De La Rosa O., D’Aubeterre R., 2019. Situation of goat farming in Venezuela and Colombia (in Spanish: Situación de la ganadería caprina en Venezuela y Colombia). In: C. Santos Sotomaior, P.M. Dayenoff Rucik, V.H. Parraguez Gamboa, ALEPRyCS (Editors). Sheep, Goats and Camelids in Latin America: Production, Health and Marketing (in Spanish: Ovejas, cabras y camélidos en Latinoamérica: producción, salud y comercialización). PUCPRESS. Curitiba (Brasil), pp. 217-220, https://doi.org/10.7213/B45-565

Dwyer C.M., Conington J., Corbiere F., Holmøy I.H., Muri K., Nowak R., Rooke J., Vipond J., Gautier J.-M., 2016. Improving neonatal survival in small ruminants: science into practice. Animal 10, 449-459, https://doi.org/10.1017/S1751731115001974

Gowane G.R., Chopra A., Prakash V., Arora A.L., 2010. Estimates of (co)variance components and genetic parameters for body weights and first greasy fleece weight in Malpura sheep. Livest. Sci. 131, 94-101, https://doi.org/10.1016/j. livsci.2010.03.006

Gregory K.E., Cundiff L.V., 1980. Crossbreeding in beef cattle: evaluation of systems. J. Anim. Sci. 51, 1224-1242, https:// doi.org/10.2527/jas1980.5151224x

Harris D.L., Stewart T.S., Arboleda C.R., 1984. Animal breeding programs: systematic approach to their design. USDA-ARS Adv. Agric. Technol. AAT-NC-8

Jembere T., Dessie T., Rischkowsky B., Kebede K., Okeyo A.M., Haile A., 2017. Meta-analysis of average estimates of genetic parameters for growth, reproduction and milk production traits in goats. Small Rumin. Res. 153, 71-80, https://doi. org/10.1016/j.smallrumres.2017.04.024

Koots K.R., Gibson J.P., Smith C., Wilton J.W., 1994. Analyses of published genetic parameter estimates for beef production traits. 1. Heritability. Anim. Breed. Abstr. 62, 309-338

Kruuk L.E.B., Hadfield J.D., 2007. How to separate genetic and environmental causes of similarity between relatives. J. Evol. Biol. 20, 1890-1903, https://doi.org/10.1111/j.14209101.2007.01377.x

INE (Instituto Nacional de Estadística), 2011. Geoenvironmental Report 2011. Aragua State (In Spanish: Informe geoambiental 2011. Estado Aragua). Instituto Nacional de Estadística, Caracas (Venezuela), pp. 197, https://www.ine.gob.ve/documentos/ Ambiental/Princlndicadores-/pdf/Informe_Geoambiental_ Aragua.pdf

Leroy G., Baumung R., Boettcher P., Scherf B., Hoffmann I., 2016. Sustainability of crossbreeding in developing countries; definitely not like crossing a meadow. Animal 10, 262-273, https://doi.org/10.1017/S175173111500213X

Lu C.D., Miller B.A., 2019. Current status, challenges and prospects for dairy goat production in the Americas. Asian-Australas. J. Anim. Sci. 32, 1244-1255, https://doi.org/10.5713/ ajas. 19.0256 
Lynch M., Walsh B., 1998. Genetics and Analysis of Quantitative Traits. Sinauer Associates Inc. Sunderland, MA (USA), pp. 980

Maniatis N., Pollott G.E., 2003. The impact of data structure on genetic (co)variance components of early growth in sheep, estimated using an animal model with maternal effects. J. Anim. Sci. 81, 101-108, https://doi.org/10.2527/2003.811101x

Matika O., van Wyk J.B., Erasmus G.J., Baker R.L., 2003. Genetic parameter estimates in Sabi sheep. Livest. Prod. Sci. 79, 17-28, https://doi.org/10.1016/S0301-6226(02)00129-X

McHugh N., Pabiou T., McDermott K., Wall E., Berry D.P., 2017. Impact of birth and rearing type, as well as inaccuracy of recording, on pre-weaning lamb phenotypic and genetic merit for live weight. Trans. Anim. Sci. 1, 137-145, https://doi.org/10.2527/ tas2017.0015

Menezes L.M., Sousa W.H., Cavalcanti-Filho E.P., Gama L.T., 2016. Genetic parameters for reproduction and growth traits in Boer goats in Brazil. Small Rumin. Res. 136, 247-256, https://doi. org/10.1016/j.smallrumres.2016.02.003

Meza-Herrera C.A., Menendez-Buxadera A., Serradilla J.M., LopezVillalobos N., Baena-Manzano F., 2019. Estimates of genetic parameters and heterosis for birth weight, onemonth weight and litter size at birth in five goat breeds. Small Rumin. Res. 174, 19-25, https://doi.org/10.1016/j. smallrumres.2019.02.018

Morris C.A., Wheeler M., Foote B.J., 2011. Relationships between live weight and herd-test traits in a Saanen goat herd in New Zealand. New Zealand J. Agric. Res. 54, 315-320, https://doi. org/10.1080/00288233.2011.609177
Mrode R.A., 2014. Linear Models for the Prediction of Animal Breeding Values. CAB International. Wallingford (UK), pp. 360, https:// doi.org/10.1079/9781780643915.0000

Räsänen K., Kruuk L.E.B., 2007. Maternal effects and evolution at ecological time-scales. Funct. Ecol. 21, 408-421, https://doi. org/10.1111/j.1365-2435.2007.01246.X

Scholtens M.R., Peterson S., Gunson K., Gunson A., Lopez-Villalobos N., 2018. Genetic evaluation of dairy sheep in a New Zealand flock. New Zealand J. Agric. Res. 61, 81-91, https://doi.org/1 0.1080/00288233.2017.1393757

Shokrollahi B., Baneh H., 2012. (Co)variance components and genetic parameters for growth traits in Arabi sheep using different animal models. Genet. Mol. Res. 11, 305-314, https://doi. org/10.4238/2012.February.8.5

Van Vleck L.D., Boldman K.G., 1993. Sequential transformation for multiple traits for estimation of (co)variance components with a derivative-free algorithm for restricted maximum likelihood. J. Anim. Sci. 71, 836-844, https://doi.org/10.2527/1993.714836x

Visser C., 2019. A review on goats in southern Africa: An untapped genetic resource. Small Rumin. Res. 176, 11-16, https://doi. org/10.1016/j.smallrumres.2019.05.009

Willham R.L., 1972. The role of maternal effects in animal breeding: III Biometrical aspects of maternal effects in animals. J. Anim. Sci. 35, 1288-1293, https://doi.org/10.2527/ jas1972.3561288x

Zhang C., Yang L., Shen Z., 2008. Variance components and genetic parameters for weight and size at birth in the Boer goat. Livest. Sci. 115, 73-79, https://doi.org/10.1016/j.livsci.2007.06.008 